\title{
Pengaruh Komposisi Serat Wlingi (Mansaiang) Terhadap Sifat Kekuatan Tarik
}

\author{
Sutrisno \\ Program Studi Teknik Mesin, Universitas Merdeka Madiun, Jl. Serayu No.79, Madiun, 63133 \\ E-mail: sutrisno@unmer-madiun.ac.id
}

\begin{abstract}
The purpose of this study was to determine the effect of the composition of the material using the wlingi fiber fraction with polyester resin on tensile strength. The materials used in this study were Wlingi fiber and BQTN polyester resin. Making was done by hand lay up process. After reaching the desired holding time, the mold is put into the oven and processed and the specimen is removed from the mold. After obtaining four specimens of wlingi fiber variations, the tensile strength testing process was carried out according to ASTM 638. The results of this test indicate that the composition of the material with a wlingi fiber weight fraction of $40 \%$ Tensile strength of $118.76 \mathrm{MPa}$, a strain of $1.32 \mathrm{~mm} / \mathrm{mm}$, and a modulus of elasticity of 12355 MPa.
\end{abstract}

Keywords —: tensile strength; wlingi fiber; BQTN resin.

\section{PENDAHULUAN}

Serat alam seperti jute, pisang, rosella, rami dan kenaf dapat dijadikan penguat yang baik pada komposit dengan matrik termoset atau termoplastik. Sebagian besar serat alam yang berasal dari tumbuhan mempunyai sifat-sifat mekanik yang baik dan densitas yang rendah. Oleh karena itu, serat alam berpotensi menjadi penguat yang sangat baik pada struktur ringan.

Beberapa keuntungan penggunaan serat alam, antara lain dapat diperbaharui (renewable), berlimpah, murah, dapat terbiodegradasi (biodegradable), tidak mencemari lingkungan dan tidak beracun. Walaupun tak sepenuhnya menggeser, namun penggunaan serat alam menggantikan serat sintesis adalah sebuah langkah bijak dalam menyelamatkan kelestarian lingkungan dari limbah yang dibuat dan keterbatasan sumber daya alam yang tidak dapat diperbaharui (Prayetno, 2007).

Berbagai macam tanaman serat tumbuh subur di Indonesia, seperti kenaf, rosella, rami, dan abaca. Dewasa ini, produksi serat alam sudah cukup tinggi yaitu: kenaf 970.00 ton/tahun, rosella 250.000 ton/tahun, rami 100.000 ton/tahun, dan abaca 70.000 ton/tahun (Eichhorn dkk, 2001). Salah satu faktor pendukung tingginya produksi serat kenaf (Hibiscus Cannabinus) adalah masa tanam yang pendek ( 4 bulan), tahan di lahan yang sering banjir, kemampuan menyerap $\mathrm{CO}_{2}$ yang tinggi (30-40 ton $\mathrm{CO}_{2} /$ hektar) serta mampu menyerap logam berat dari tanah (www.kenaf-fibers.com, 2009). Di Indonesia sendiri, serat kenaf biasanya hanya dipergunakan sebagai bahan pembuat karung goni sehingga nilai ekonominya rendah. Oleh karena itu, pemanfaatan serat kenaf perlu ditingkatkan. Salah satu pemanfaatan serat kenaf yang dapat dilakukan yaitu dengan memanfaatkannya sebagai bahan panel struktur sehingga memiliki nilai ekonomi dan teknologi tinggi.

Menurut Diharjo dkk (2009) penggunaan kembali serat alam dipicu oleh adanya regulasi tentang persyaratan habis pakai produk komponen otomotif bagi negara-negara Uni Eropa dan sebagian Asia. Aplikasi panel komposit berpenguat serat kenaf sudah banyak digunakan di dunia transportasi dan telekomunikasi, diantaranya seperti mobil Toyota di Jepang, mobil Mercedez Benz di Jerman, dan produsen elektonik NEC di Jepang. Hasil riset yang dilakukan oleh Diharjo dkk (2005) yang memanfaatkan serat kenaf dan limbah serat sawit telah diaplikasikan sebagai penguat panel meja kereta eksekutif (K1) dan kereta ekonomi (K3) di PT INKA Madiun.

Peningkatan unjuk kerja bahan merupakan suatu kebutuhan pada aplikasi keteknikan. Hal ini mengharuskan pengembangan bahan teknik menjadi suatu bahan yang lebih adaptif. Penggunaan serat alam saja sebagai penguat pada suatu komposit terkadang tidak cukup untuk menjawab permasalahan itu. Oleh karena itu, kombinasi serat alam dan serat sintetis memungkinkan untuk dikembangkan. Hal tersebut dikarenakan serat sintetis memiliki beberapa keunggulan yang tidak dimiliki oleh serat alam, yaitu memiliki kekuatan tinggi. Akan tetapi serat sintetis tidak dapat terbiodegradasi, mempunyai massa jenis yang relatif tinggi, dan mahal.

Pengembangan komposit menggunakan serat alam yang dikombinasikan dengan serat sintetis adalah salah satu teknik untuk menambah kekuatan dan kekakuan dari komposit. Kombinasi serat alam dengan serat sintetis dalam matrik yang sama dapat disebut komposit hibrid. Komposit hibrid adalah suatu material yang dibuat dengan mengkombinasikan dua atau lebih serat yang berbeda dalam matrik yang sama. Walaupun beberapa jenis serat dapat disatukan dalam satu sistem hibrid, akan tetapi kombinasi hanya dua jenis serat lebih menguntungkan dari sisi ekonomi. Jenis komposit hibrid memungkinkan untuk menjaga keseimbangan antara sifat-sifat mekanik dan nilai ekonomis dari komposit (Reddy dkk, 2008).

Dari pertimbangan-pertimbangan yang telah dikemukakan diatas, maka penelitian ini perlu dilakukan untuk mengetahui kekuatan Tarik serat wlingi dengan matrik polyester, sehingga diperoleh data yang diharapkan berguna dalam aplikasi panel komposit ini secara nyata. 


\section{TINJAUAN PUSTAKA}

Reddy dkk (2008) dalam penelitiannya menyatakan bahwa kekuatan tarik dan kekerasan dari komposit hibrid serat kapokserat gelas meningkat seiring dengan bertambahnya komposisi serat gelas pada komposit hibrid. Kekuatan tarik dan kekerasan komposit hibrid lebih tinggi dari komposit yang tersusun dari penguat serat kapok saja. Perlakuan alkali NaOH $2 \%$ selama setengah jam pada serat kapok memiliki pengaruh yang signifikan pada kekuatan tarik dan kekerasan komposit hibrid serat kapok-serat gelas.

Khanam dkk (2009) meneliti komposit hibrid berpenguat serat sabut kelapa-serat sutera dalam jurnalnya yang berjudul Tensile, Flexural and Compressive Properties of Coir/Silk Fiber-reinforced Hybrid Composite. Perbandingan serat sabut dengan serat sutera adalah $1: 1$, matrik yang digunakan adalah unsaturated polyester resin. Variasi penelitian yang digunakan adalah panjang serat yaitu 1, 2 dan $3 \mathrm{~cm}$. Hasil penelitian menunjukkan kekuatan tarik, lentur dan tekan tertinggi terdapat pada komposit hibrid dengan panjang serat $2 \mathrm{~cm}$. Perlakuan alkali $\mathrm{NaOH} 2 \%$ selama 1 jam pada serat sabut menghasilkan kekuatan yang lebih tinggi dari komposit hibrid tanpa perlakuan.

Yousif dkk (2008) dalam penelitiannya yang berrjudul The Effect Treatment on Tribo-Performance of CFRP (Coir Fiber Reinforced Polyester) menyimpulkan (1) komposit CFRP tanpa perlakuan mempunyai keausan rata-rata tertinggi pada semua beban yang diaplikasikan, (2) perlakuan alkali komposit CFRP mempunyai ketahanan aus lebih baik dibandingkan dengan komposit CFRP perlakuan bleach dan tanpa perlakuan, (3) pada kenyataannya ketahanan aus dari beberapa material akan berbeda tergantung dari bentuk dan kondisi pengujian.

\section{A. Serat wlingi (Mensiang)}

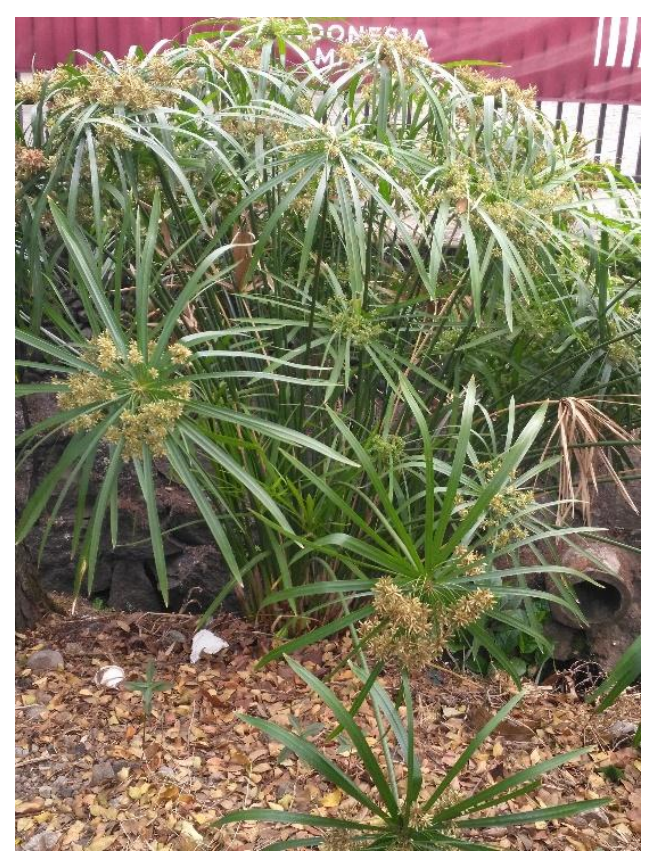

Gambar 1. Serat wlingi (Mensiang)

Sumber: https://id.wikipedia.org/wiki/Mensiang

Rumput yang berumpun kuat, tegak, beranak banyak, dengan geragih panjang yang berujung pada sebuah umbi kecil; batang menyegitiga tajam dengan sisi-sisi yang mencekung, berambut halus, $80-200 \underline{\mathrm{cm}} \times 5-10 \underline{\mathrm{mm}}$. Daun-daun dalam roset, seperti garis, $50-80 \mathrm{~cm} \times 0,5-3 \mathrm{~cm}$, sebelah bawah menyegitiga hingga melekuk dalam, sebelah atas melekuk dangkal dengan ujung datar dan sangat runcing, tepinya berambut tajam. Perbungaan terminal, tak beraturan, bentuk payung majemuk; sumbu perbungaan kasar, berambut sikat halus, 4-17 cm panjangnya; pangkalnya dengan beberapa daun pelindung yang tidak sama panjang, setidaknya 2 di antaranya lebih panjang dari perbungaan, $15-70 \mathrm{~cm}$ panjangnya; spikelet berjumlah banyak, soliter, duduk atau bertangkai, bulat telur sampai bulat telur memanjang, berujung runcing, dengan banyak bunga berjejal-jejal, 4-10 $\times$ 3,5-4 mm. Buah bulir bulat telur terbalik, dengan ujung meruncing, halus, kecokelatan, menyegitiga, 1,25-1,75 mm $\times 1 \mathrm{k} .1 \mathrm{~mm}$.

\section{B. Resin Unsaturated Polyester (UP)}

Resin Unsaturated Polyester (UP) dalam komposit ini digunakan sebagai matrik yang bertugas untuk melindungi dan mengikat serat agar dapat bekerja dengan baik serta meneruskan beban dari luar ke serat. Resin UP ini merupakan jenis resin thermoset. Resin ini mudah digunakan dalam proses hand lay-up sampai dengan proses yang komplek yaitu dengan proses mekanik seperti vacuum bag, press mold, dan injection mold. Apabila polyester dipanaskan maka tidak akan mencair dan mengalir, tetapi akan terbakar dan menjadi arang. (Prayetno, 2007). 
Penggunaan resin jenis ini dapat dilakukan dari proses hand lay up sampai dengan proses yang kompleks yaitu dengan proses mekanik. Resin ini banyak digunakan dalam aplikasi komposit pada dunia industri dengan pertimbangan harga relatif murah, curing yang cepat, warna jernih, kestabilan dimensional dan mudah penanganannya (Billmeyer, 1984). Pengesetan termal digunakan Benzoil Peroksida (BPO) sebagai katalis. Temperatur optimal adalah $80^{\circ}-130^{\circ} \mathrm{C}$, namun demikian kebanyakan pengesetan dingin yang digunakan. Metyl Etyl Keton Peroksida (MEKPO) digunakan sebagai katalis dan ditambahkan pada 1-2 $\%$ (Surdia dan Saito, 1985).

Resin yang digunakan dalam penelitian ini adalah resin Unsaturated Polyester (UP) Yukalac 157® BTQN-EX. Pemberian bahan tambahan katalis jenis methyl ethyl ketton peroxide (MEKPO) pada resin UP berfungsi untuk mempercepat proses pengerasan cairan resin (curing). Penambahan katalis dalam jumlah banyak akan menimbulkan panas yang berlebihan pada saat proses curing. Hal ini dapat menurunkan kualitas atau merusak produk komposit. Oleh karena itu pemakaian katalis sebanyak $1 \%$ dari volume resin total (PT Justus Kimia Raya, 2001).

\section{III.METODE PENELITIAN}

\section{A. Alat Penelitian}

Peralatan yang digunakan dalam pembuatan spesimen uji antara lain:

a. Timbangan Digital

Timbangan digunakan untuk menimbang seberapa beratnya resin dan serat dicampurkan sesuai dengan fraksi volumenya. Selain itu juga untuk menguji hasil komposit apakah sesuai dengan fraksi volume yang telah ditentukan.

b. Cetakan

Cetakan komposit terbuat dari besi cor.

c. Gelas ukur dan suntikan

Gelas ukur berfungsi untuk menakar matrik sesuai dengan hasil perhitungan. Suntikkan berfungsi untuk menakar katalis yang akan dicampurkan sesuai dengan hasil perhitungan.

d. Malam (lilin)

Malam atau lilin berfungsi sebagai bahan perapat sambungan plat pada cetakan agar campuran matrik dan katalis tidak merembes atau bocor keluar cetakan yang menyebabkan void pada tiap pojok cetakan.

e. Jangka sorong

Jangka sorong digunakan untuk mengukur panjang, lebar dan tebal spesimen.

f. Gerinda

Gerinda tangan digunakan untuk membentuk spesimen uji impak

g. Press Mold

Balok penekan ini digunakan untuk menekan komposit.

h. Gelas corong dan pengaduk

Gelas corong berfungsi untuk memasukkan campuran matrik dan serat ke dalam cetakan komposit agar tidak tumpah. Pengaduk berfungsi sebagai alat pengaduk antara matrik dan katalis agar proses pencampuran dapat merata.

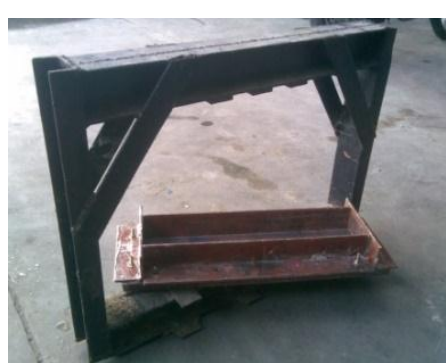

(a) peralatan cetak

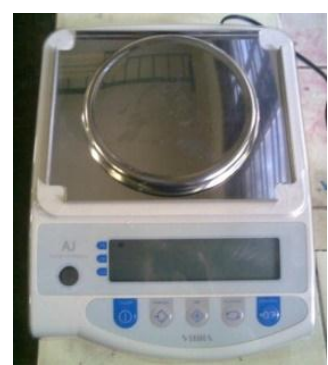

(b) timbangan digital

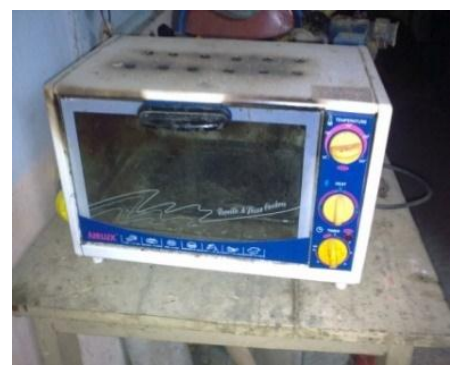

(c) oven

Gambar 3. Peralatan yang dibutuhkan dalam pembuatan komposit

\section{B. Bahan Penelitian}

Berikut ini bahan-bahan yang digunakan dalam pembuatan komposit hibrid antara lain :

Tabel 1. Bahan yang digunakan dalam penelitian

\begin{tabular}{|c|c|c|c|c|}
\hline No. & Bahan & Jenis & Sumber & Keterangan \\
\hline 1. & Serat sabut wlingi & Mensiang & Lokal & $\begin{array}{c}\text { Sebagai penguat } \\
\text { komposit }\end{array}$ \\
\hline 2. & Katalis & Methyl Ethyl Ketton & PT. Justus Kimia Raya & Mempercepat \\
\hline
\end{tabular}


Website : http://pilar.unmermadiun.ac.id/index.php/pilarteknologi

\begin{tabular}{|c|c|c|c|c|}
\hline \hline & & Peroxide (MEKPO) & Semarang & pengerasan \\
\hline 3. & Resin & $\begin{array}{c}\text { Unsaturated Polyester } \\
\text { Resin BQTN }\end{array}$ & $\begin{array}{c}\text { PT. Justus Kimia Raya } \\
\text { Semarang }\end{array}$ & $\begin{array}{c}\text { Sebagai } \\
\text { pengikat/matrik } \\
\text { komposit }\end{array}$ \\
\hline
\end{tabular}

\section{IV.HASIL DAN PEMBAHASAN}

Hasil pengujian tarik komposit variasi prosentase serat wlingi dan matrik polyester didapatkan data rata-rata hasil tegangan tarik sebagai berikut :

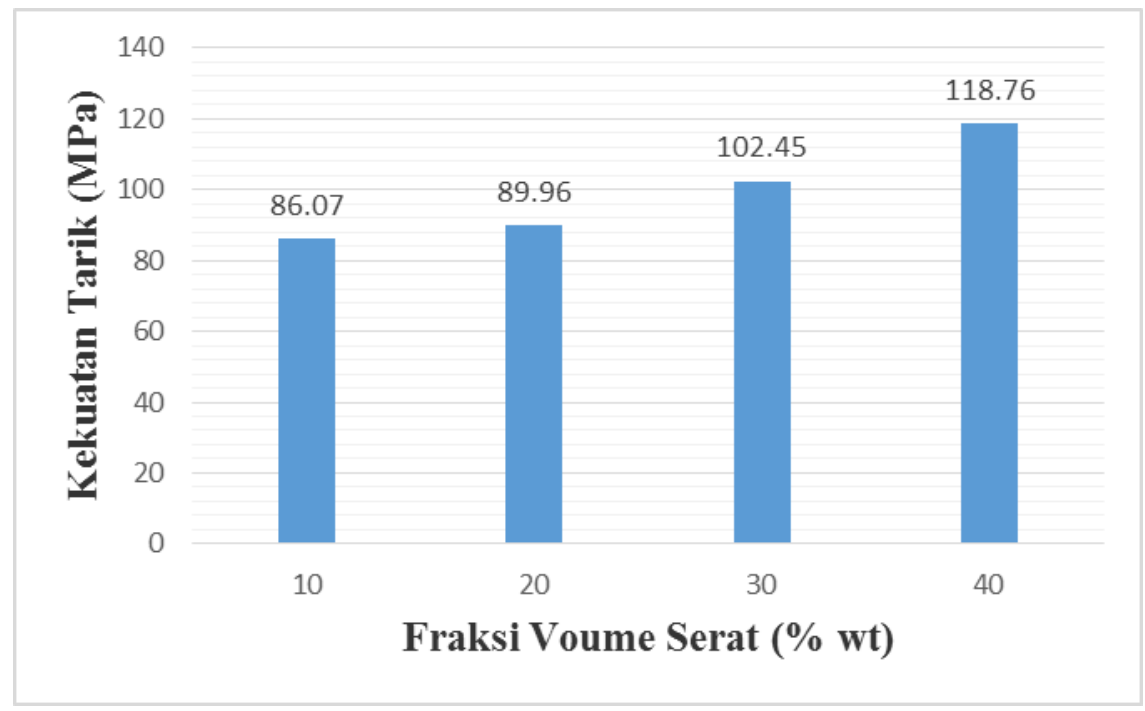

Gambar 4. Grafik hubungan kekuatan tarik serat wlngi dan resin polyester

Pada Gambar 4 grafik hubungan antara tegangan tarik dan fraksi volume variasi serat wlingi dan prsentase fraksi matrik polyester, menunjukkan bahwa nilai tegangan tarik tertinggi terjadi pada spesimen 4 dengan fraksi volume $40 \%$ serat yaitu sebesar 118,76 MPa, sedangkan untuk nilai tegangan tarik terendah terjadi pada spesimen 1 dengan fraksi volume $10 \%$ yaitu sebesar 86.07 Mpa. Kenaikan tegangan tarik pada spesimen 4 dipengaruhi oleh daya ikat antara serat dan matrik yang sempurna serta komposisi serat wlingi yang lebih banyak dibandingkan variasi lainnya. Tegangan tarik akan mengalami kenaikan seiring dengan meningkatnya fraksi volume serat mansiang (Paryanto, dkk., 2012).

Hasil pengujian tarik komposit variasi serat wlingi dengan matrik polyester didapatkan data rata-rata hasil regangan tarik sebagai berikut :

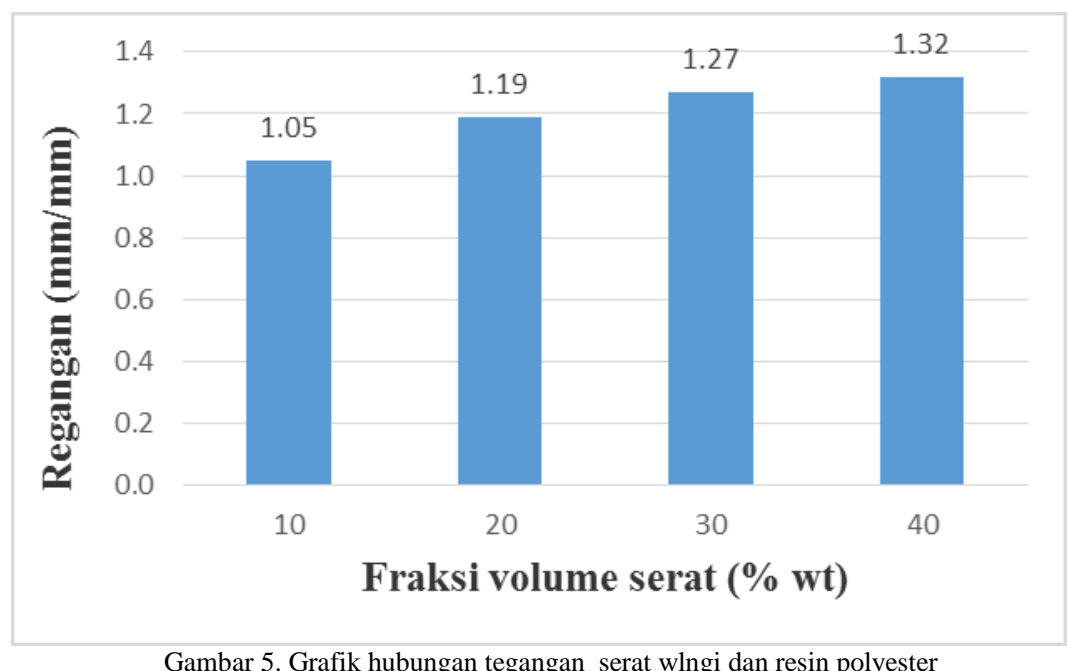

Pada gambar 5 menunjukkan grafik hubungan antara regangan dengan fraksi volume variasi serat wlingi menunjukkan bahwa nilai regangan tarik tertinggi terjadi pada spesimen 4 dengan fraksi volume $40 \%$ serat yaitu sebesar $1,32 \%$, sedangkan nilai regangan tarik terendah terjadi pada spesimen 1 dengan fraksi volume $10 \%$ yaitu sebesar 1,05\%. Pada grafik diatas dapat dilihat bahwa fraksi volume 1 sampai fraksi volume 4 mengalami kenaikan yang dimana kenaikan secara drastis terjadi pada 
fraksi volume 3 ke fraksi volume 4. Kenaikan regangan tarik disebabkan karena serat nanas mempunyai nilai regangan tarik yang lebih tinggi dibandingkan dengan matrik polyester (Paryanto, dkk., 2012).

Dari hasil pengujian tarik komposit variasi serat wlingi dengan matrik polyester didapatkan data rata-rata hasil modulus elastisitas sebagai berikut :

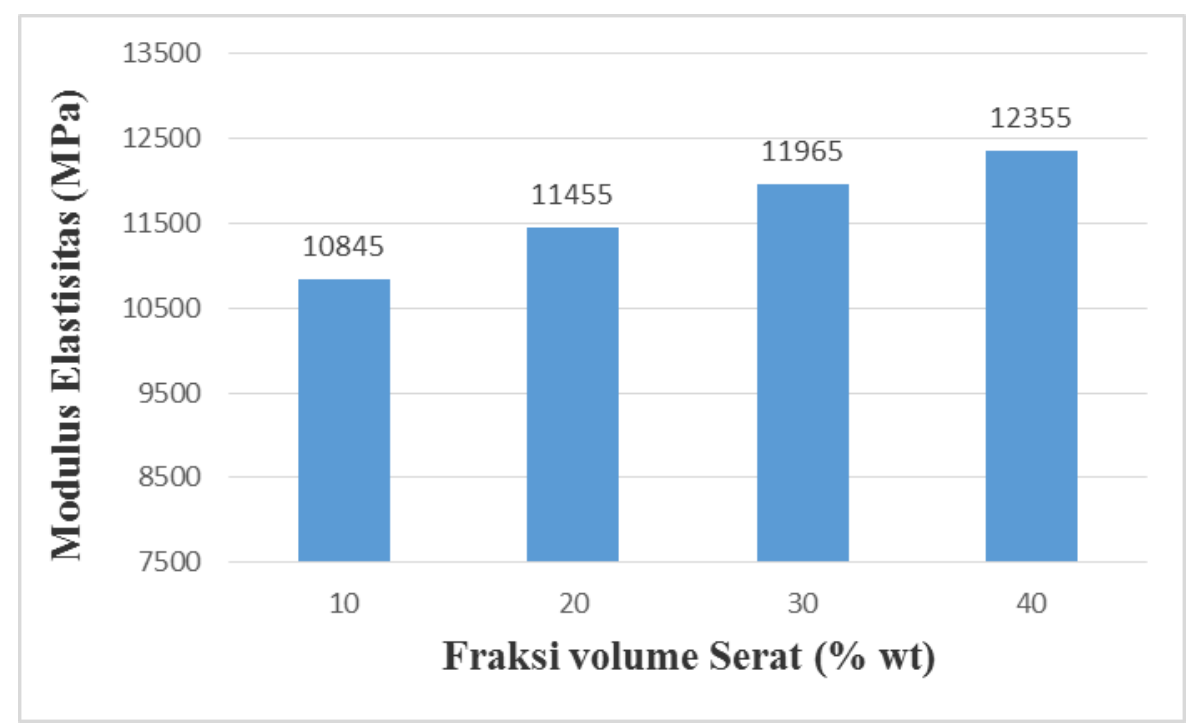

Gambar 6. Grafik hubungan modulus elastisitas serat wlngi dan resin polyester

Pada gambar 6 menunjukkan grafik hubungan antara modulus elastisitas dengan fraksi volume variasi serat wlingi menunjukkan bahwa nilai modulus elastisitas tertinggi terjadi pada spesimen 4 dengan fraksi volume $40 \%$ serat yaitu sebesar $12355 \mathrm{MPa}$, sedangkan nilai modulus elastisitas terendah terjadi pada spesimen 1 dengan fraksi volume $10 \%$ yaitu sebesar $10845 \mathrm{MPa}$. Komposit variasi serat wlingi pada spesimen 4 memiliki nilai modulus elastisitas tertinggi disebabkan karena ikatan silang yang terjadi antara filler dan matriks dimana semakin baik ikatan silang yang terjadi maka semakin baik pula komposit yang dihasilkan, dengan demikian modulus elastisitas juga akan mengalami peningkatan (Azwar, 2009).

Nilai modulus elastisitas pada spesimen 4 komposit variasi serat nanas wlingi lebih besar dibandingkan dengan nilai modulus elastisitas komposit serat nanas dengan resin polyester. Nilai modulus elastisitas pada spesimen 4 komposit variasi serat wlingi adalah $12355 \mathrm{Mpa}$, sedangkan nilai modulus elastisitas komposit serat wlingi dengan resin polyester adalah $10845 \mathrm{Mpa}$.

\section{KESIMPULAN}

Berdasarkan hasil pengujian dan analisis data maka dapat ditarik kesimpulan sebagai berikut : Komposit variasi serat wlingi dengan matrik polyester didapatkan nilai kekuatan tarik tertinggi sebesar 118,76 Mpa, regangan sebesar 1,32\%, dan nilai modulus elastisitas sebesar $12355 \mathrm{MPa}$ Mpa pada fraksi volume $40 \%$ serat.

\section{VI.DAFTAR PUSTAKA}

Annual Book of ASTM Standards. 2003. "Annual Book of ASTM standart”. West Conshohocken.

Anonim, 2010, Overview of Composite Processes, ACMA (American Composite Manufacturers Association) Available Online at www.acmanet.org

Anuar H., Ahmad, S.H., Rasid, R., and Zakaria, S., 2005, Tensile Behavior and Morphological Studies of TPNR-KF-CF Hybrid Composite, American Journal of Applied Science (Special Issue): 34-39.

Berthelot J.M., 1984, Composite Materials Mechanical Behavior and Structural and Analysis, Valloise, France.

Billmeyer, Fred W., 1984, Texbook of Polymer Science. Singapore : John Wiley \& Sons (SEA) Pte. Ltd.

Bismarck, A., Askargorta, I.A., Lamphe, T., Wielaye, B., Stamboulis, A., Skenderovich, I., and Limbach, H.H., 2002, Surface Characterization of Flax, Hemp and Cellulose Fibres: Surface Properties and the Water Uptake Behavior, Polymer Composite Vol 23, no. 5. of Kenaf Fibers, 16 ${ }^{\mathrm{TH}}$ International Conference on Composite Materials, Kyoto.

Diharjo, K., Jamasri, Soekrisno, dan Rochardjo, H.S.B., 2006, Kajian Sifat Fisis-Mekanis dan Akustik Komposit Serat Kenaf-Polyester dengan Core Kayu Sengon Laut, Hasil Riset Pendahuluan - Dissertasi, Pascasarjana, UGM, Yogyakarta.

Diharjo, K., Masykuri, M., Budi, L., dan Gunadi, A., 2007, Rekayasa dan Manufaktur Bahan Komposit Sandwich Berpenguat Serat Kenaf Dengan Care Limbah Kayu Sengon Laut Untuk Komponen Gerbong Kereta Api. Lembaga Penelitian dan Pengabdian Masyarakat, Universitas Sebelas Maret, Surakarta.

Eichhorn S.J., Baillie, C.A., Zafeiropoulos, N., and Mwaikambo, L.Y., 2001, Review Current International Research into Selullosic Fibres and Composite Journal of Materials Science, pp. 2107-2131

Gibson, O.F., 1994, Principle of Composite Materials, McGraw Hill Company, New York, USA.

Jones R. M., 1999, Mechanics of Composite Materials, McGraw Hill, New York.

Khanam, P.N., Reddy, G.R., Raghu, K., and Naidu, V.S., 2010, Tensile, Flexural, and Compressive Properties of Coir/Silk Fiber-Reinforced Hybrid Composites, Journal of Reinforced Plastic and Composite, Vol. 29, No 14.

Malau, V., dan Widyaparaga, A., 2008, Pengaruh Perlakuan Panas Quench Dan Temper Terhadap Laju Keausan, Ketangguhan Impak, Kekuatan Tarik dan Kekerasan Baja Xw 42 Untuk Keperluan Cetakan Keramik, MEDIA TEKNIK, Tahun XXX, No. 2. 
Website : http://pilar.unmermadiun.ac.id/index.php/pilarteknologi

Mishra, S., Misra, M., Triphati, M., Nayak, S., and Mohanty, A., 2000, Potentiality of Pineapple Leaf Fiber as Reinforcement in PALF-Polyester Composite: Surface Modification and Mechanical Performance, J Reinf Plast Compos 20 (4):321-324.

Reddy, G.V., Naidu, S.V., and Rani, S.T.., 2008, Kapok/Glass Polyester Hybrid Composite: Tensile and Hardness Properties, Journal of Reinforced Plastic and Composite, Vol. 27, No 16-17.

Schwartz, M.H., 1984, Composite Material Handbook, McGraw Hill, New York.

Surdia, T., dan Saito, S., 1985. Pengetahuan Bahan Teknik. Dainippon Gita Karya Printing. Jakarta.

Liu, X.Y., and Day. G.C., 2007. Surface Modification And Micromechanical Properties OfJute Fiber Mat Reinforced Polypropylene. State-Key Laboratory of Chemical Engineering, East China University of Science and Technology, 130 Meilong Road, Shanghai 200237, P. R. China.

Yousif, B.L, Leong, O.B., Ong, L.K., and Jye, W.K., 2009, The Effect of Treatment on Tribo-Performance of CFRP Composite, Recent Patents on Materials Science 2009, 2, 67-74s. 